\title{
Sustainable Mining - a Case Study in Canadian Practice
}

\author{
D.H. Steve Zou ${ }^{*}$ and Cui Lin \\ Mineral Resource Engineering, Dalhousie University, Halifax, Canada
}

\begin{abstract}
This paper first discusses the basic attributes of sustainable mining and the responsibilities of various steak holders including mining companies, governments, and engineers. It is followed by a brief overview of the current practice on regulations, inspections, waste management and mine closure planning in Canadian mining industry. A case study is then presented as an example of sustainable mining where mine planning, mineral recovery, environment protection, reclamation and community development were integral parts of the overall strategy. A comparison of the mine site before and after mining is made to demonstrate the "best practice" in modern mining.
\end{abstract}

Keywords: mineral resources management, mining, environment protection, community development.

\section{Sustainability in Mineral Resource Development}

Extraction of mineral resources and other natural resources on the Earth has been and will continue to be an essential activity necessary to support human's life. We live on the planet and depend on the available resources to survive. The extracted materials form the base to support modern life.

However, we must be aware of the fact that mineral resources are limited on the Earth and may not last forever. Every time we extract one ton of materials, there is one ton less. They are not able to regenerate or regrow. One can ask a simple question: How long will they last? Or, is there anything left for our great grandchildren and many generations to come?

The answer is not simple. Some minerals have become scarce or about to deplete. Some minerals may last longer. The reserve of a type of minerals depends on what we have discovered and the minable amount depends on accessibility and technology we have. Even if there are minerals in the deep ground, we may be limited by our technological capability.

At the same time, we also need to understand the action of mineral extraction from the ground and the consequences of that action. Mineral extraction is a very hard work. We must break the ground to extract the ore, either through surface mining or underground mining. This action means disturbance of the land where we live. The disturbance is much more visible in surface mining than underground mining. The disturbed land, if not properly reclaimed after mining, is not going to be reusable. The very purpose of extracting minerals from the ground is to support our life but the action has a negative impact on our life.

How can we reduce and limit disturbance of land from the action of minerals extraction? How can we make the disturbed land reusable? These issues must be properly addressed and a balance achieved.
The ores mined from the ground must be processed to extract the useful minerals and to produce materials we need for manufacturing useful products. This process involves milling, grinding, a series of processing and refining, often with chemical reagents. As a result, mineral processing generates huge amount of waste materials and discharges the wastes to the surrounding area, some of which may pollute the environment.

Once again, to protect the land we live on, the waste materials must be disposed properly and necessary measures taken to limit or eliminate pollution to the environment.

It has become clear that sustainable mining means not only making mineral resources development last longer with no waste of resources but also limiting and/or eliminating negative environment impact. To achieve that goal, we must address properly all of the aforementioned issues.

Therefore, sustainability in mineral resources development can be summarized as follows:

a) Extraction of mineral resources in a responsible way: maximizing recovery of resources without wasting,

b) Removal or reduction of footprints: removing any footprint of mining or at least limiting land disturbance to the minimum through proper reclamation,

c) Elimination or reduction of negative environment impact: eliminating environment pollution or at least limiting it to the minimum by proper disposal of waste materials.

\section{Responsibilities in Modern Mining}

Based on the previous discussions, we can see the importance of ensuring extraction of mineral resources sustainable. To achieve sustainability, we need to act on the three aspects as mentioned above.

The responsibility of achieving the sustainability rests on the shoulders of all stakeholders, from mine operators, governments to engineers. Some stakeholders may however bear much bigger responsibility than others.

* Corresponding Author: D.H. Steve Zou, steve.zou@ dal.ca, phone: +1 902-4943977

Copyright @ 2017 Canamaple Academia Services, http://press.camdemia.ca

DOI: 10.15273/gree.2017.02.045 


\subsection{Responsibilities of Mining Companies Sub heading of your paper}

Mining companies are in the forefront of mineral resources extraction and apparently have the biggest role to play. A mine operator should not compromise its responsibility in sustainable mining while trying to meet the bottom line of its business and should implement throughout its operation the three points in sustainability identified above.

During planning and policy making, effort should be made to recover all economically minable reserves and not leave lower grade ores behind. It is not an acceptable practice to chase profit by extracting high grade ores only. We must value the limited resources and be responsible for the future generations.

At the same time, a well-laid out reclamation plan should be in place to remove footprints of land disturbance and eliminate negative environment impact the operation may have caused. Mining footprints can only be dealt with after completion of mine operation while measures to reduce environment impact can be implemented throughout the mining process and thereafter.

Examples of removing mining footprints may include restoration of the disturbed land to a usable condition, such as a recreation park for community use or a place for wild life. A mine pit may also be restored through a proper process as a pond or watershed for water habitat. Apparently there are many ways to achieve the goal, depending on the situation of each case.

Environment impact is primarily caused by the large amount of waste rocks disposed on site and the effluents, which may contain polluting elements, discharged during or after mining. Waste rocks and tailings left open site are prone to acid drainage and pollution. Solution to this problem has to be in place from the beginning of a mining operation.

Examples of waste disposal may include use of waste rocks and tailings for underground backfill of mined openings, surface cover of waste rock piles to avoid mine acid drainage, under water disposal of waste rocks and tailings, etc. Any method to be used should be properly designed to meet environment requirements.

\subsection{Responsibilities of Governments}

The responsibilities for governments in maintaining the sustainability of mineral resources development is also very important. In considering the three points of sustainability identified in the first section, the government which is responsible for mineral resource development should have policies in place to ensure that the limited mineral resources are extracted in a responsible way and the environmental issues generated by mineral extractions are dealt with properly.

It is perhaps proper to say that in many countries there are some policies in place dealing with mineral resources extractions. However implementation of these policies and enforcement of relevant regulations may vary widely. Policies are normally implemented through corresponding regulations, while regulations are enforced by proper monitoring and inspections, followed by remedy measures.

Apparently, the role of a government is not only in simply making policies but also in making sure these policies are followed. As a remedy measure, those who violate the regulations should face certain consequences, from warning, suspension of operation until the requirements are met, to closure of operation.

In this process, the inspectors should be able to perform their duties independently, free from influence from any third parties. They should also hold a high standard in their profession and carry out duties fairly without bias.

\subsection{Responsibilities of Engineers}

Engineers are professionals. There are professional standards we are bond to follow. That means, we are not only to perform the duties assigned from employers - the mining companies, but also maintain our professional standard, part of which is to protect the public interests. The three points in sustainability of mineral resources extraction identified above are for the public interest both in the short term and in the long term. Apparently we engineers have our responsibilities in sustainable mining.

Such responsibilities may be achieved in our daily work. For example, make sure no economically minable ores are wasted in mine planning, wastes are not disposed without proper measure to avoid pollution, and discharges of effluents meet the environment standards, etc.

\section{Current Practice in Canadian Mining Industry}

Mining has played an important role in Canadian economy for many decades. Canada is the world's top four producer of a number of minerals (e.g., Potash; Uranium, Niobium; Cobalt, Aluminum, Tungsten; Nickel, Salt, Sulphur and Titanium. MAC 2015). Mining activities spread over every province and territories.

It is not the intention of the author here to give a comprehensive review on mining activities and mining regulations in Canada. Rather, the author will give a brief description of the current practice relevant to sustainable mining.

Needless to say, in the early stages of mining, up to early 20th century, mining was not well regulated like in many other countries. As a result, abandoned mines, improperly disposed mine wastes and tailings caused various environmental issues and became serious concerns. In response, regulations were gradually put in place to protect the environment and ensure the sustainability of mining.

In Canada, the provincial governments are directly responsible for regulating mining within their jurisdictions. At present, mining regulations are in place in all provinces where mining operation is active. For example, like every other province, Nova Scotia has a Mineral Resource Act (MRR 2004) outlining the details of various regulations from prospecting, permit application to mine productions.

Involvement of the Federal government is limited to activities on Crown land and of Crown corporations. There 
is however a set of general rules on projects which may have impact on the environment. A rigorous process is to be followed in the approval process including public inquiry and consultations with local communities.

After mining activities are completed, the mines site are to be properly rehabilitated. That calls for a mine closure plan, such as that described in Cowan (2010). For a new mine to open, a reclamation plan and adequate funding for mine closure is first required. That means, before a mine is open the company needs to demonstrate how it is going to close the mine and reclaim the site. Apparently, proper plan of waste disposal and measures to avoid environment pollution are required. Only after all requirements are met, will a mining permit be issued.

To ensure the regulations are followed by mining companies, there is an inspection process by a provincial inspector, who is usually also a professional engineer with professional training. Inspection may be carried on a regular basis if necessary or whenever a problem is reported or when something happened.

An inspector goes to a mine site often without notice the operator. If there is any violation, the inspector may issue orders to the mine operator to comply within a fixed time frame. Failure to comply may result in various penalties up to suspension of operation permit.

In general, a mining company has established policies in its operation to meet the government regulations and its employees are required to follow. The Mining Association of Canada, made of mining companies, has established a program "Towards Sustainable Mining" in 2004 to promote sustainable mining and govern the activities of its members in mining and mineral processing (MANS 2016). It's mandatory for members to produce mineral products "in the most socially, economically and environmentally responsible way".

On the individual bases, engineers have to follow engineering ethics. Before a professional engineer's license is approved, an engineer is required to write a test on ethics. Part of the test is to make sure professional engineers put the public interest first.

\section{A Case Study of Sustainable Mining}

To demonstrate what the mining practice is like in Canada at present, a case study will be shown below. For privacy reason, the company name and location will not be revealed.

\subsection{Historical background}

This is a coal mine, located in a small town within $300 \mathrm{~m}$ from the nearest residential area. The area is generally flat with little hilling.

There was mining activities in late 1800's and early 1900 's in this area, in small scales and mostly through shallow underground workings (Figure 1). The early mining extracted most of the easily accessible, high grade coal in thick seams, leaving lower grade and smaller pockets here and there. Many of the mine workings were unknown after so many years and no mine plans were available. They apparently posed a danger for any attempt to mine the remaining coal.

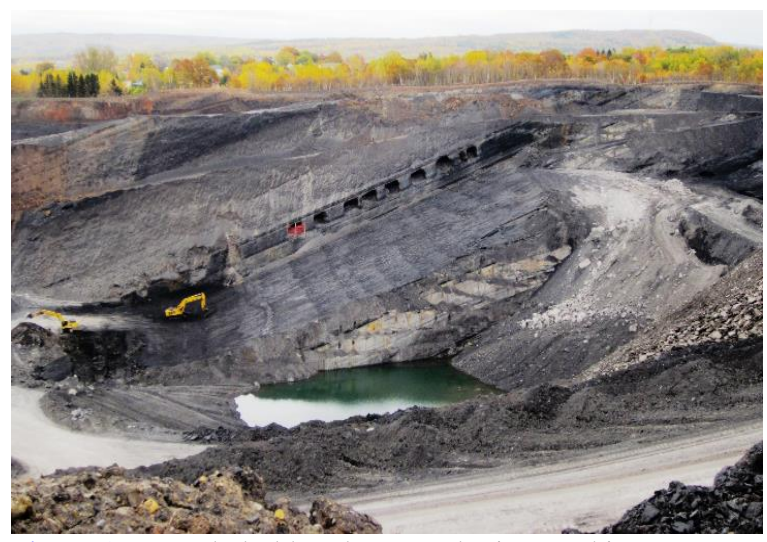

Figure 1. Revealed old underground mine workings.

Over twenty years ago, a mine operator had an interest to recover the remaining coal in that area with modern mining technology. The coal seams were within $80 \mathrm{~m}$ depth below the surface. With the deposit so close to residential area, noise and dust control became the priority of operation. Blasting operation would not be acceptable.

\subsection{Mine operation and waste rocks handling}

It became apparent that after a feasibility study, it would only be economically viable to mine the remaining coal by surface mining using large equipment and it would only be acceptable without blasting.

The deposit, dipping $20^{\circ}-25^{\circ}$ to the north, outcropped in the East and plunged to the West, nearly $80 \mathrm{~m}$ deep, stretching over a few hundred meters. The surface layout of the mine is shown in Figure 2. The selected mining method was a modified strip/open pit mining.

The deposit was divided into several sections and mining started from the east progressing to the west without partition. The overall operation was similar to a conventional open cast mining and waste rocks from new excavations were used to fill the previously mined area. However, in each stage, it was like a small open pit operation.

Coal mining and rock removal were completed by separate truck and shovel operations. Top materials were stripped in advance (Figure 3) in stages and stored separately for later use in reclamation. This operation was also completed by shovel and truck combination. 


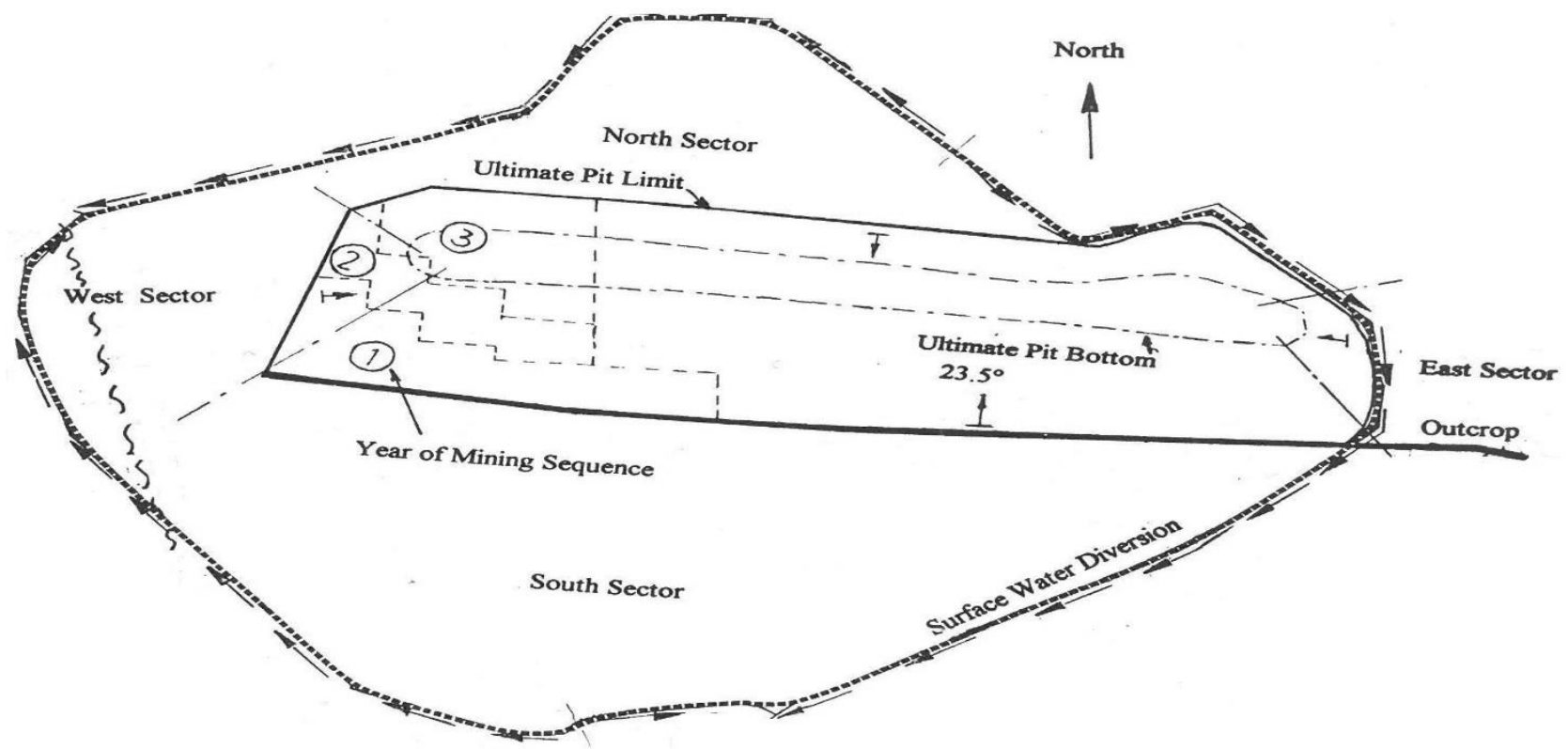

Figure 2. Surface layout of a mine operation.

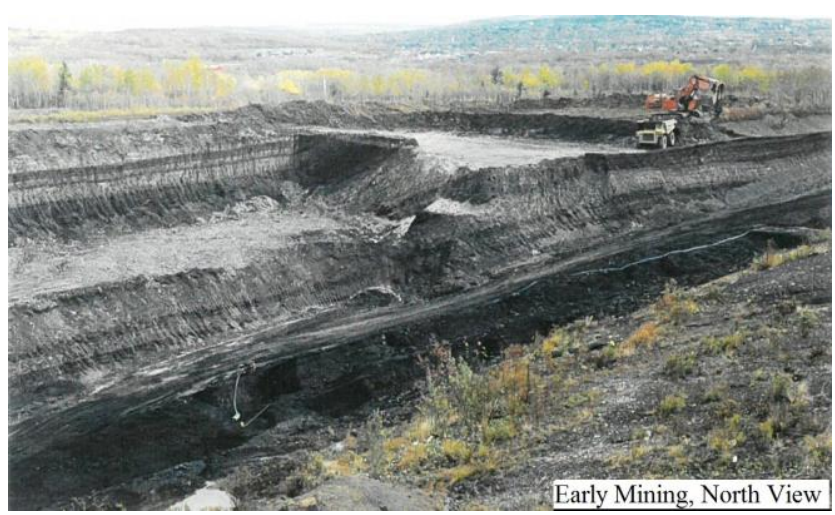

Figure 3. Advanced stripping.

In the first stage, waste rocks were stored on the footwall side in the south. Trucks and later conveyor belt were used for transferring the rocks. Figure 4 indicates the operations in the early stage, viewed in two opposite directions (Zou 1995).

Once the first pit reached its ultimate depth, mining started in the next pit, where waste rocks were hauled by trucks to the first pit as backfill. The process continued towards the west. As one can image, the original pit is not large enough to hold all the waste rocks because of volume expansion of loose materials. Extra waste rocks were also piled up in the south side.

When the first pit was filled up to the ground level, the area was immediately covered with top soil and sod. This process continued for the rest of the mine.

\subsection{Mine closure and reclamation}

As noted above, mining and reclamation were carried out in a progressive process. When mining was completed, the entire area, including the stock pile of waste rocks on the
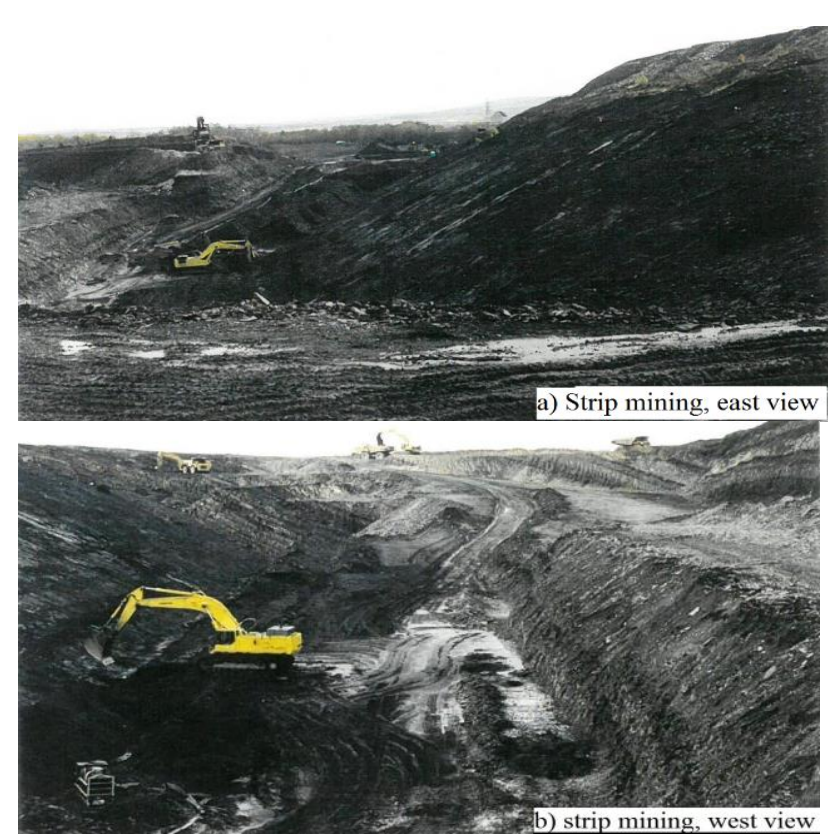

Figure 4. Views of mining operation.

footwall side, was contoured to match the surrounding area. It was then covered with top materials and topped up with sod.

The mine closure and reclamation plan started from the beginning and engaged the local community. With their input, the reclaimed area was made as a tracking field for recreational use by community. The waste rock pile on the south side was properly contoured with vegetation and a water tower was built on top of it due to its high position to supply water to the whole community (Figure 5). 
A comparison of the site during mining and after reclamation viewed from the water tower place is shown in Figure 6.

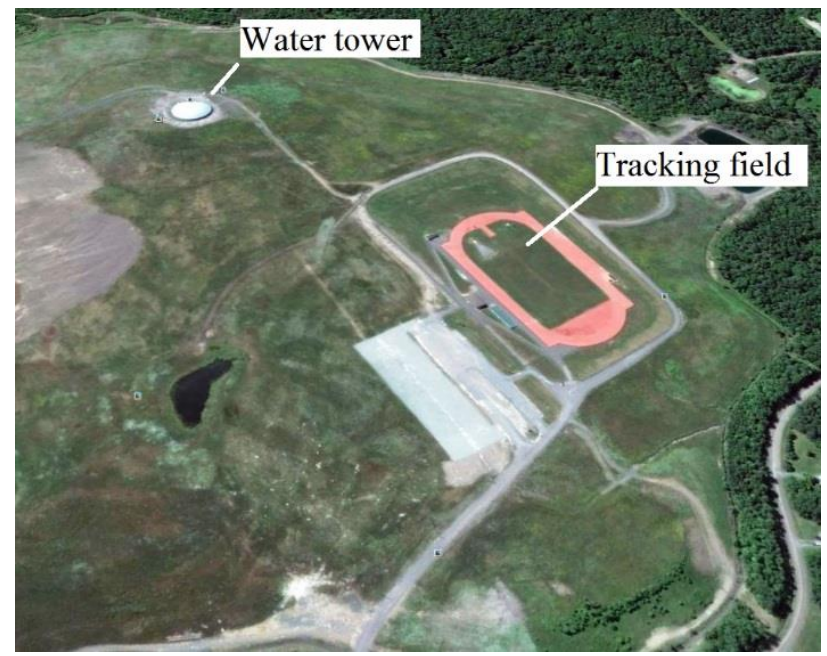

Figure 5. Bird view of the reclaimed mine site, looking south-west.

\section{Closing Remarks}

In closing, sustainability in mineral resource development would mean the three aspects: a) Extraction of mineral resources in a responsible way with consideration to the future generations, b) Removal or reduction of footprints and, c) Elimination or reduction of negative environment impact.

It is possible through proper planning and consultation with various stakeholders to reduce or even eliminate mining footprints and to benefit the society.

The responsibility rests all stakeholders who need to work together and ensure that extraction of mineral resources is sustainable for many generations to come.

\section{References}

Cowan, W.R., W.O. Mackasey and J.G.A. Robertson, 2010. National orphaned/abandoned mines initiative.

MAC (Mining Association of Canada), 2015. Facts and figures of the Canadian mining industry.

MANS (Mining Association of Nova Scotia), 2016. http://tmans.ca/.

MRR (Mineral Resource Regulations of Nova Scotia), 2004. https://novascotia.ca/just/regulations/regs/mrregs.htm.

Zou, D.H., 1995. Mine design report (to a client).
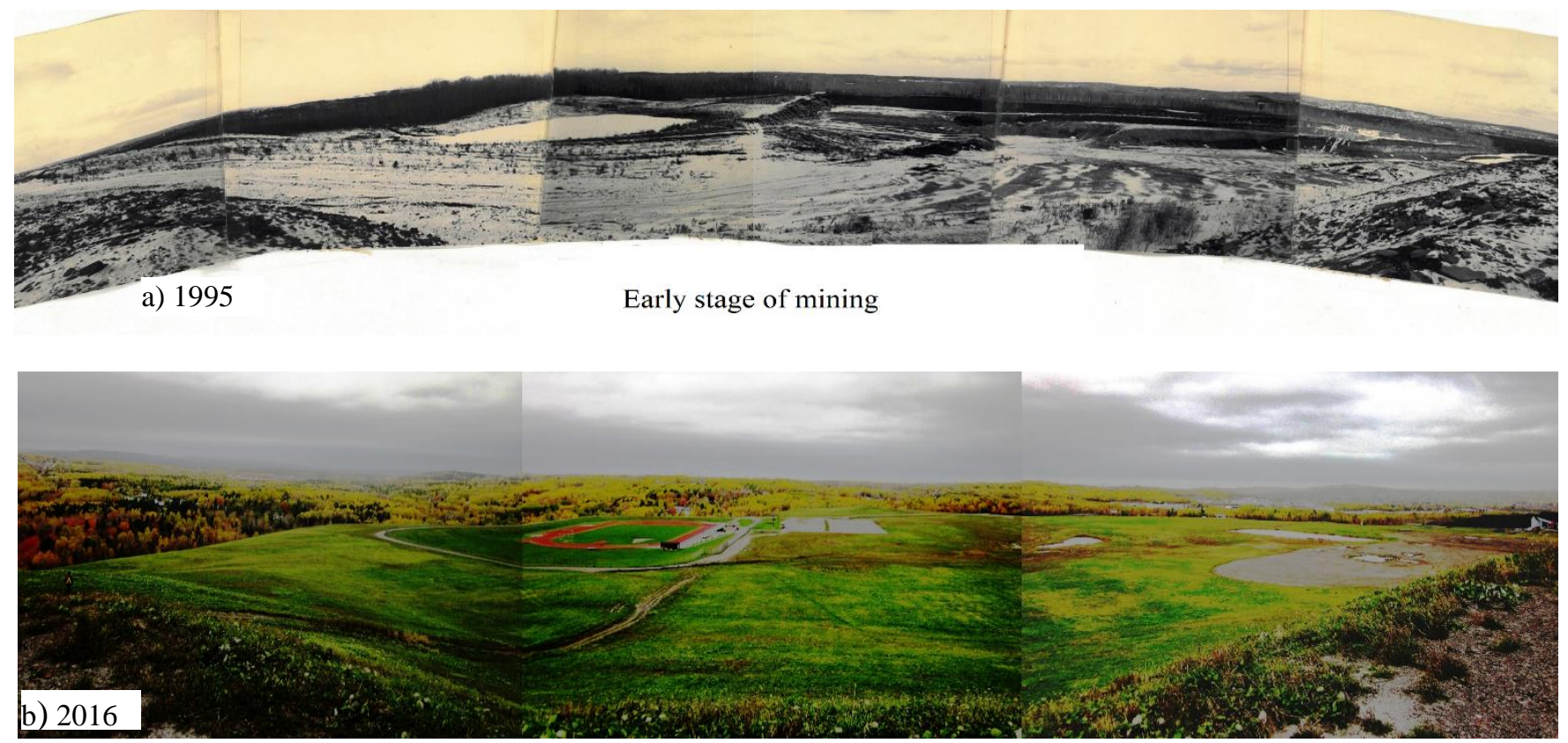

Figure 6. a) Early stage of surface mine operation, b) Surface condition after reclamation. 